\title{
ACCURACY OF CBCT, DIGITAL AND CONVENTIONAL RADIOGRAPHY IN EVALUATING THE SHAPING PERFORMANCE OF A NOVEL NITI ROTARY SYSTEM (AN IN VITRO STUDY)
}

\author{
Sherif A. Ammar*, Nihal E. Sabet ${ }^{* *}$ and Hagar A. Bastawy ${ }^{* * *}$
}

\begin{abstract}
Aim: This study was designed to evaluate and compare the shaping abilities of ProTaper Gold and the ProTaper Universal systems using cone beam computed tomography (CBCT), digital and conventional radiography.

Materials and Methods: Forty mesiobuccal root canals of extracted mandibular first molars with curvature ranging between $25-60^{\circ}$ according to Schneider's technique were selected and prepared using either ProTaper Gold (group I) or ProTaper Universal (group II). Root canals were scanned using CBCT, digital and conventional radiography before and after preparation for measurement of canal transportation and centering ratio at three levels $(3,6$ and $9 \mathrm{~mm})$ from the apex.
\end{abstract}

Results: ProTaper Gold instruments resulted in lower mean canal transportation and higher mean centering ratio compared to ProTaper Universal instruments at 3,6 and 9mm levels when conventional, digital radiographic or CBCT radiography were used, with a statistically significant difference, at $9 \mathrm{~mm}$ when the conventional and digital radiographic methods were used; and at 3 $\mathrm{mm}$ when CBCT radiographic method was used.

Conclusions: ProTaper Gold instruments are more able to maintain the original canal configuration than did ProTaper Universal instruments considering canal transportation and centering ability. CBCT proved to present more details than conventional and digital periapical radiographs at the three tested levels.

KEYWORDS: Protaper Gold, Protaper Universal, Cone Beam Computed Tomography (CBCT), Digital radiography, Conventioal radiography.

\footnotetext{
* Teaching Assistant of Endodontics, Endodontic Department, Faculty of Dentistry, Egyptian Russian University ** Professor of Endodontics, Cairo University

*** Associate Professor of Endodontics, Endodontic Department, Faculty of Dental Medicine for girls, Al-Azhar University, Cairo, Egypt.
} 


\section{INTRODUCTION}

Mechanical preparation of the root canal system is one of the most important stages of endodontic treatment. The aim of instrumentation is to remove vital and necrotic tissues from the root canal system, along with infected root dentin creating the space that allows irrigants and antibacterial medicaments to more effectively eradicate bacteria and eliminate bacterial by-products. Therefore, canal instrumentation can be considered as the essential phase that eliminates infection ${ }^{(1)}$.

Several rotary systems have been introduced and improved recently, with the development of new rotary file designs, techniques and manufacturing methods in order to overcome difficulties in root canal preparation, simplify the procedures and reduce instrumentation time. $\mathrm{Ni}-\mathrm{Ti}$ instruments are much more flexible with a modulus of elasticity that is about one-fifth of the value of stainless-steel files also special thermal and mechanical treatments introduced the new $\mathrm{M}$-wires and $\mathrm{CM}$-wires with higher flexibility and fatigue resistance (2). Therefore, Ni-Ti rotary instruments produce a more centered canal preparation3, with less transportation than stainless steel instruments ${ }^{(3)}$.

ProTaper Universal (PTU) is a widely used rotary instruments manufactured from the conventional super elastic Ni-Ti wire, is characterized by good cutting efficiency and a progressive taper that allows for less contact with canal walls and good torsional resistance. Being made of the conventional $\mathrm{Ni}-\mathrm{Ti}$ wire, PTU files produced more canal transportation and straightening of curved canals compared to the more flexible M- wires and CM- wires (4-6).

ProTaper Gold (PTG) system has the same design as PTU system with a triangular cross section and a variable progressive taper. ProTaper Gold has been metallurgically enhanced through post machining heat-treatment of CM-wire, which is known to enhance flexibility, improves the centering abilities of the files in the canal and decreases the canal transportation during preparation of curved canals ${ }^{(4,7,8)}$. The heat-treated files also demonstrated enhanced fatigue resistance compared to conventional NiTi files as claimed by the manufacturer ${ }^{(9)}$.

Several evaluation methods for specimens were adopted as tooth sectioning ${ }^{(10)}$, which was not accurate, then the conventional and digital radiographic techniques, which presented a 2D image of a 3D object ${ }^{(11,12)}$. CBCT has emerged as a powerful tool for evaluation of root canal morphology because it is accurate as anatomic sectioning and gives 3D information of teeth and jaws ${ }^{(11,13)}$.

The aim of this study was to evaluate and compare the shaping abilities of ProTaper Gold and the ProTaper Universal systems using CBCT, digital and conventional radiographic techniques.

\section{MATERIALS AND METHODS}

Forty extracted human mandibular first molars were selected that fulfilled the following criteria; mature apices without noticeable root defects, mesial roots having 2 separate mesial canals and apical foramina, with an average length of 12-15 $\mathrm{mm}$ and angle of curvature ranging between $25^{\circ}$ $60^{\circ}$ according to Schneider's technique ${ }^{(14)}$.

Surface and calcified debris were removed using an ultrasonic scaler and then teeth were disinfected in sodium hypochlorite $5.25 \%$ for 15 minutes. After complete cleaning, teeth were autoclaved to ensure sterility and then stored in saline until used. All crowns were sectioned at $2 \mathrm{~mm}$ above the cementoenamel junction using diamond disc under constant water cooling and then the access cavity was refined with Endo-Z bur. All samples were hemi-sectioned at the furcation level with a safe sided diamond disc.

Meisobuccal canals were checked for apical patency with a \# $10 \mathrm{~K}$-file until it was just visible from the apex, then $1 \mathrm{~mm}$ was subtracted from this 
length to establish the working length. \# $15 \mathrm{~K}$-file was introduced to the working length to create a glide path.

Using a digital calliper and a permanent marker, the mesial roots were marked at three parts; apical, middle and coronal $(3 \mathrm{~mm}, 6 \mathrm{~mm}$ and $9 \mathrm{~mm}$ ) from the apex respectively, then placed in a mount made of a silicon-based impression material to maintain a fixed film/sensor-object-source position during the conventional and digital radiography ${ }^{(9)}$. The radiographic mount is composed of a paralleling film/sensor holder which held the samples parallel to the long axis of the roots and as near as possible to the roots, therefore, the X-ray tube and the central $\mathrm{X}$-ray beam were aligned perpendicular to the roots.

Samples were randomly divided into two experimental groups (I and II) according to the NiTi file system used during canal instrumentation $(n=20)$, where group I: samples were instrumented with ProTaper Gold (PTG), while group II: samples were instrumented with ProTaper Universal (PTU).

Pre-instrumentation conventional and digital radiographs were taken with \#15 K-files inside the canals at the working length by placing the mounts in the paralleling device. The exposure parameters for the conventional and digital radiographs were $(0.4 \mathrm{~s} ; 60 \mathrm{KV}, 6 \mathrm{~mA})$ and $(0.16 \mathrm{~s} ; 60 \mathrm{KV}, 6 \mathrm{~mA})$ respectively. The conventional radiographs were digitalized by scanning them, then they were imported to EzDent-i software for measurements. Then pre-instrumentation (CBCT) scans were made with exposure time 0.04 seconds, operating at 90 $\mathrm{kV}$ and $15 \mathrm{~mA}$ with slice thickness of $0.125 \mathrm{~mm}$. Image reconstruction was performed using Romexis 3D software. Pre-instrumentation mesial and distal dentin thickness were measured at the three levels (3, 6 and $9 \mathrm{~mm}$ from the apex) to determine canal transportation and centering ratio.

Root canals were instrumented either with The ProTaper Gold or ProTaper Universal instruments in an electric motor "Endo-Mate DT, NSK, Nakanishi
Inc., Tokyo, Japan" with a 16:1 reduction handpiece at speed of $300 \mathrm{rpm}$ with a torque of $3 \mathrm{~N} / \mathrm{cm}$ for $\mathrm{SX}, \mathrm{S} 1$, and $\mathrm{S} 2$ instruments, $1.5 \mathrm{~N} / \mathrm{cm}$ for $\mathrm{F} 1$ files and $2 \mathrm{~N} / \mathrm{cm}$ for $\mathrm{F} 2$ files following the manufacturer instructions. In both groups (I and II), root canal preparation was done starting with Sx file up to file F2 as master apical file (MAF) to complete apical preparation.

After each instrument use, irrigation with 2 $\mathrm{ml}$ of freshly prepared $2.6 \%$ sodium hypochlorite $(\mathrm{NaOCl})$ solution dispensed through a 31-gauge Navi-Tip flexible irrigation needle, where the needle was inserted as deep as possible into the root canal without binding. Ethylenediamintetraacetic acid (EDTA) gel was used as a lubricating agent.

After instrumentation, the samples were radiographed/scanned under the same conditions as the initial radiographs/scans. The amount of canal transportation was assessed at each pre-determined level by measuring the shortest distance from the edge of uninstrumented canal to the periphery of the root (mesial and distal) and then comparing these measurements with the same measurements obtained from the instrumented images ${ }^{(15)}$.

The following formula was used for the calculation of transportation:

$$
[(\mathrm{A} 1-\mathrm{A} 2)-(\mathrm{B} 1-\mathrm{B} 2)]
$$

According to this formula, a result other than 0 indicates that transportation has occurred in the canal ${ }^{(15)}$. A positive value represented transportation to the outer canal wall (mesial wall), while a negative value represented transportation of the prepared canal to the inner wall (distal wall). Pre and post-instrumentation standardized CBCT axial view images were used to calculate the canal transportation at the pre-determined levels.

The mean centering ratio indicates the ability of the instrument to stay centered in the canal. It was calculated for each pre-determined level by using the following ratio:

$$
(\mathrm{A} 1-\mathrm{A} 2) /(\mathrm{B} 1-\mathrm{B} 2) \text { or }(\mathrm{B} 1-\mathrm{B} 2) /(\mathrm{A} 1-\mathrm{A} 2) \text {. }
$$


If these numbers are not equal, the lower figure is considered as the numerator of the ratio. According to this formula, a result of 1 indicates perfect centering ${ }^{(15)}$.

\section{Statistical analysis:}

Data were presented as mean values and standard deviation (SD). Data were explored for normality by checking the distribution of data and using tests of normality (Kolmogorov-Smirnov and Shapiro-Wilk tests). For parametric data; One-way ANOVA test was used to compare among the different groups. For non-parametric data; Mann-Whitney U test was used to compare between two instruments. KruskalWallis test was used to compare among the different groups. Mann-Whitney U test with Bonferroni adjustment was used for pair-wise comparisons when Kruskal-Wallis test was significant. The significance level was set at $\mathrm{P} \leq 0.05$. Statistical analysis was performed using IBM ${ }^{\circledR}$ SPSS $®$ Statistics Version 21 for windows (SPSS Inc., Chicago, IL).

\section{RESULTS}

\section{Shaping abilities of the two tested instruments us- ing CBCT, digital and conventional radiography}

\section{Canal Transportation (Table 1)}

With the conventional and digital radiographic methods, the results showed that, ProTaper Gold instruments produced significantly less canal transportation compared to ProTaper Universal instruments at the coronal level $(\mathrm{P} \leq 0.05)$. However, Mann Whitney U test showed no statistically significant difference between the two tested instruments at the apical and middle levels $(\mathrm{P}>0.05)$ (Fig 1,2).

With CBCT radiographic methods, the results showed that, ProTaper Gold instruments produced significantly less canal transportation compared to ProTaper Universal instruments at the apical level $(\mathrm{P} \leq 0.05)$. However, Mann Whitney $\mathrm{U}$ test showed no statistically significant difference between the two tested instruments at the middle and coronal levels $(\mathrm{P}>0.05)$.

TABLE (1): Descriptive analysis of canal transportation $(\mathrm{mm})$ between the two tested instruments.

\begin{tabular}{|c|c|c|c|c|c|c|}
\hline \multirow{2}{*}{$\begin{array}{c}\text { Radiographic } \\
\text { technique }\end{array}$} & \multirow{2}{*}{ Level } & \multicolumn{2}{|c|}{$\begin{array}{l}\text { Group I } \\
\text { (PTG) }\end{array}$} & \multicolumn{2}{|c|}{$\begin{array}{l}\text { Group II } \\
\text { (PTU) }\end{array}$} & \multirow{2}{*}{ P-Value } \\
\hline & & Mean & SD & Mean & SD & \\
\hline \multirow{3}{*}{$\begin{array}{c}\text { Conventional } \\
\text { radiograph }\end{array}$} & Apical (3mm) & 0.05 & 0.03 & 0.09 & 0.1 & 0.242 \\
\hline & Middle $(6 \mathrm{~mm})$ & -0.01 & 0.07 & -0.06 & 0.13 & 0.565 \\
\hline & Coronal $(9 \mathrm{~mm})$ & -0.01 & 0.12 & -0.13 & 0.14 & $0.001 *$ \\
\hline \multirow{3}{*}{ Digital radiograph } & Apical (3mm) & 0.06 & 0.06 & 0.09 & 0.06 & 0.121 \\
\hline & Middle (6mm) & -0.05 & 0.14 & -0.04 & 0.16 & 0.841 \\
\hline & Coronal $(9 \mathrm{~mm})$ & -0.05 & 0.16 & -0.16 & 0.16 & $0.023^{*}$ \\
\hline \multirow{3}{*}{ CBCT } & Apical (3mm) & 0.006 & 0.010 & 0.013 & 0.011 & $0.005^{*}$ \\
\hline & Middle $(6 \mathrm{~mm})$ & -0.01 & 0.06 & -0.07 & 0.11 & 0.429 \\
\hline & Coronal (9mm) & -0.06 & 0.11 & -0.12 & 0.16 & 0.052 \\
\hline
\end{tabular}




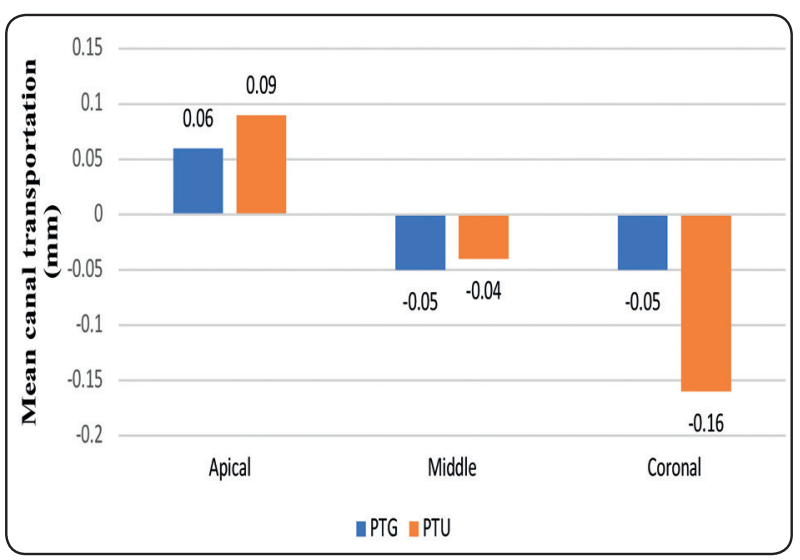

Fig. (1): A bar chart comparing the mean canal transportation after using ProTaper Gold and ProTaper Universal instruments using digital radiography.
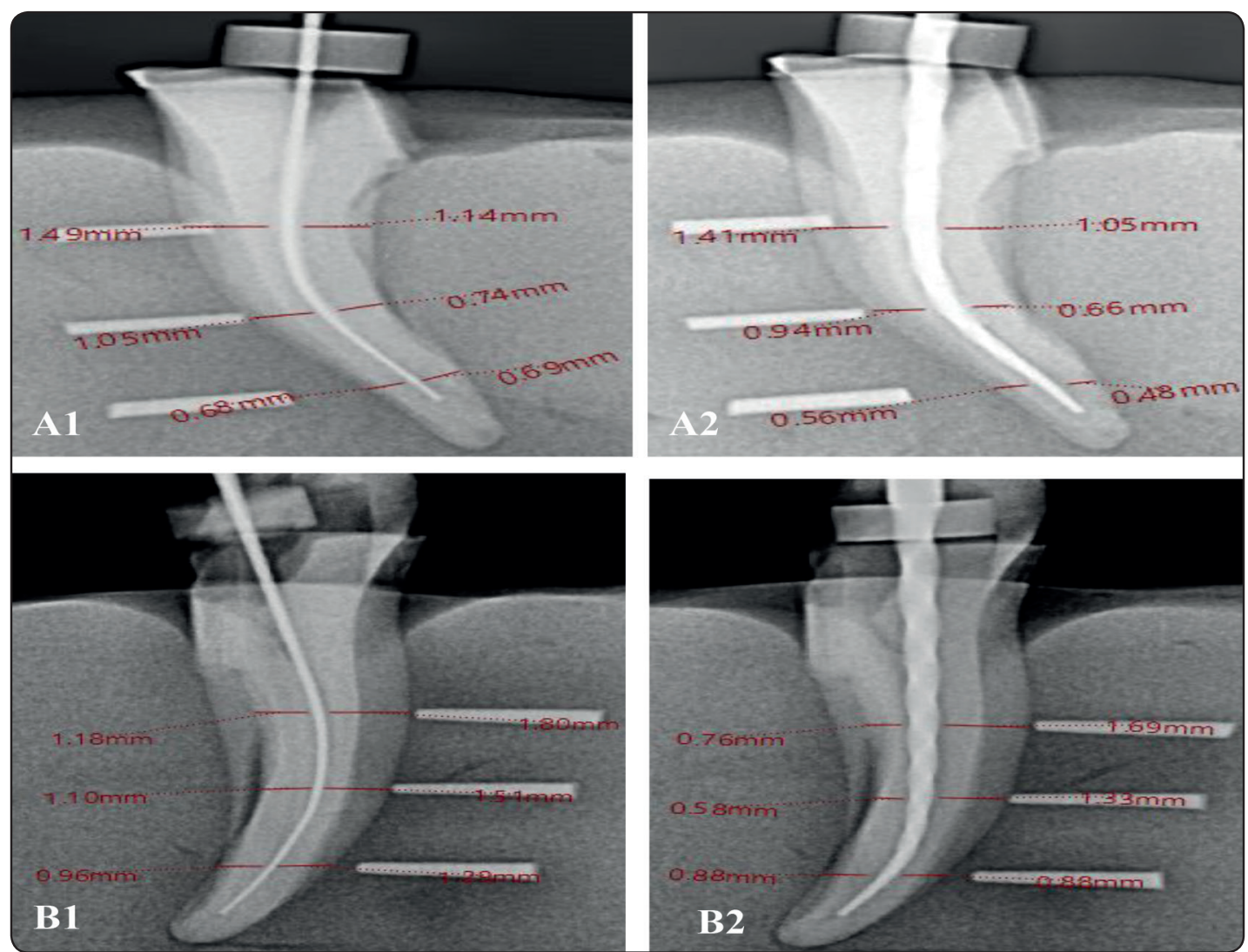

Fig. (2): A1-Digital radiographic pre-instrumentation image of a specimen showing pre-instrumentation measurements at 3,6 and $9 \mathrm{~mm}$ from the apex. A2- Digital radiographic post-instrumentation image of a specimen prepared with ProTaper Gold (PTG) showing post-instrumentation measurements at 3,6 and 9mm from the apex. B1- Digital radiographic preinstrumentation image of a specimen showing pre-instrumentation measurements at 3,6 and 9mm from the apex. B2Digital radiographic post-instrumentation image of a specimen prepared with ProTaper Universal (PTU) showing postinstrumentation measurements at 3,6 and $9 \mathrm{~mm}$ from the apex.

\section{Centering Ratio: (Table 2)}

With the conventional radiographic method, the results showed that, ProTaper Gold instruments produced significantly more centered canal preparation compared to ProTaper Universal instruments at the apical and coronal levels $(\mathrm{P} \leq$ 0.05). However, Mann-Whitney $\mathrm{U}$ test showed that, there was no statistically significant difference between the two tested instruments at the middle level $(\mathrm{P}>0.05)$.

With the digital radiographic method, the results showed that, ProTaper Gold instruments produced more centered canal preparation compared to 
ProTaper Universal instruments at the apical, middle and coronal levels. However, Mann-Whitney U test showed that, there was no statistically significant difference between the two tested instruments at the three level $(\mathrm{P}>0.05)$.

With CBCT radiographic method, the results showed that, ProTaper Gold instruments produced significantly more centered canal preparation compared to ProTaper Universal instruments at the apical level $(\mathrm{P} \leq 0.05)$. However, Mann Whitney U test showed no statistically significant difference between the two tested instruments at the middle and coronal levels $(\mathrm{P}>0.05)$.
The accuracy of the radiographic techniques in evaluating canal transportation and centering ratio: (Table 3) and (Fig 3,4)

\section{Canal Transportation}

Within group I (PTG), Kruskal-Wallis test showed that there was a statistically significant difference among the three radiographic methods in the mean canal transportation when ProTaper Gold instruments were used $(\mathrm{P} \leq 0.05)$. Mann-Whitney $\mathrm{U}$ test with Bonferroni adjustment test revealed that, the CBCT radiographic method showed the statistically highest mean canal transportation. However, there was no statistically significant

TABLE (2): Descriptive analysis of centering ratio between the two tested instruments.

\begin{tabular}{|c|c|c|c|c|c|c|}
\hline \multirow{2}{*}{$\begin{array}{c}\text { Radiographic } \\
\text { technique }\end{array}$} & \multirow[t]{2}{*}{ Level } & \multicolumn{2}{|c|}{$\begin{array}{c}\text { Group I } \\
\text { (PTG) }\end{array}$} & \multicolumn{2}{|c|}{$\begin{array}{c}\text { Group II } \\
\text { (PTU) }\end{array}$} & \multirow[t]{2}{*}{ P-Value } \\
\hline & & Mean & SD & Mean & SD & \\
\hline \multirow{3}{*}{$\begin{array}{c}\text { Conventional } \\
\text { radiograph }\end{array}$} & Apical (3mm) & 0.73 & 0.19 & 0.54 & 0.30 & $0.021 *$ \\
\hline & Middle $(6 \mathrm{~mm})$ & 0.68 & 0.24 & 0.55 & 0.23 & 0.087 \\
\hline & Coronal (9mm) & 0.62 & 0.23 & 0.42 & 0.26 & $0.014 *$ \\
\hline \multirow{3}{*}{$\begin{array}{c}\text { Digital } \\
\text { radiograph }\end{array}$} & Apical (3mm) & 0.58 & 0.18 & 0.52 & 0.25 & 0.448 \\
\hline & Middle $(6 \mathrm{~mm})$ & 0.53 & 0.20 & 0.49 & 0.20 & 0.553 \\
\hline & Coronal $(9 \mathrm{~mm})$ & 0.55 & 0.23 & 0.38 & 0.28 & 0.051 \\
\hline \multirow{3}{*}{ CBCT } & Apical $(3 \mathrm{~mm})$ & 0.97 & 0.05 & 0.88 & 0.07 & $<0.001 *$ \\
\hline & Middle $(6 \mathrm{~mm})$ & 0.72 & 0.23 & 0.65 & 0.26 & 0.401 \\
\hline & Coronal (9mm) & 0.63 & 0.21 & 0.50 & 0.32 & 0.122 \\
\hline
\end{tabular}

* Significant at $\mathrm{P} \leq \mathbf{0 . 0 5}$

TABLE (3): Descriptive analysis of the accuracy of conventional, digital and CBCT radiographic methods.

\begin{tabular}{|c|c|c|c|c|c|c|c|c|}
\hline \multirow{3}{*}{ Radiographic technique } & \multicolumn{4}{|c|}{ Group I (PTG) } & \multicolumn{4}{|c|}{ Group II (PTU) } \\
\hline & \multicolumn{2}{|c|}{ Transportation } & \multicolumn{2}{|c|}{ Centering ratio } & \multicolumn{2}{|c|}{ Transportation } & \multicolumn{2}{|c|}{ Centering ratio } \\
\hline & Mean & SD & Mean & SD & Mean & SD & Mean & SD \\
\hline Conventional radiograph & $0.01^{\mathrm{a}}$ & 0.05 & $0.68^{\mathrm{a}}$ & 0.17 & -0.03 & 0.05 & $0.50^{\mathrm{a}}$ & 0.19 \\
\hline Digital radiograph & $-0.01^{\mathrm{a}, \mathrm{b}}$ & 0.07 & $0.55^{\mathrm{b}}$ & 0.11 & -0.03 & 0.06 & $0.47^{\mathrm{a}}$ & 0.15 \\
\hline CBCT & $-0.02^{\mathrm{b}}$ & 0.03 & $0.78^{a}$ & 0.11 & -0.06 & 0.05 & $0.68^{\mathrm{b}}$ & 0.12 \\
\hline$P$-value & \multicolumn{2}{|c|}{$0.043 *$} & \multicolumn{2}{|c|}{$<0.001 *$} & \multicolumn{2}{|c|}{0.144} & \multicolumn{2}{|c|}{$<0.001^{*}$} \\
\hline
\end{tabular}

*: Significant at $P \leq 0.05$, Different superscripts in the same row are statistically different. 


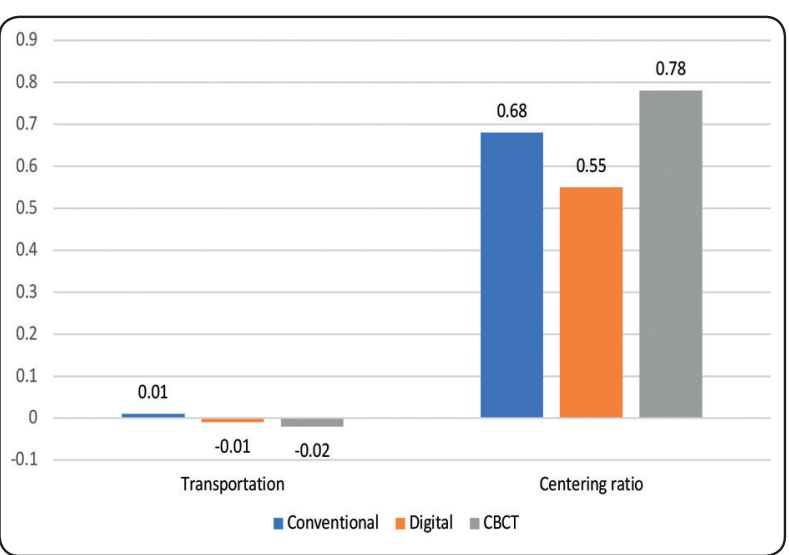

Fig. (3): A bar chart comparing the mean values of conventional, digital and $\mathrm{CBCT}$ radiographic methods in measuring transportation and centering ability in PTG group.

difference in the mean canal transportation produced by conventional and digital radiographic methods or digital and CBCT radiographic methods when ProTaper Gold instruments were used.

Within group II (PTU), Kruskal-Wallis test showed that, there was no statistically significant difference among the three radiographic methods in the mean canal transportation when ProTaper Universal instruments were used $(\mathrm{P}>0.05)$.

\section{Centering Ratio:}

Within group I (PTG), Kruskal-Wallis test showed that there was a statistically significant difference among the three radiographic methods in the mean centering ratio when ProTaper Gold instruments were used $(\mathrm{P} \leq 0.05)$. Mann-Whitney $\mathrm{U}$ test with Bonferroni adjustment test revealed that the digital radiographic method showed the statistically lowest mean centering ratio. However, there was no statistically significant difference in the mean centering ratio produced by conventional and $\mathrm{CBCT}$ radiographic methods when ProTaper Gold instruments were used.

Within group II (PTU), Kruskal-Wallis test showed that there was a statistically significant difference among the three radiographic methods in

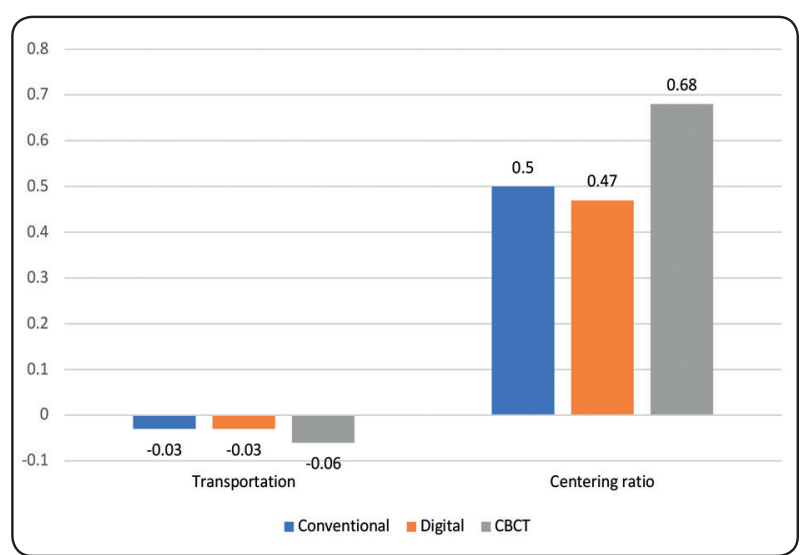

Fig. (4): A bar chart comparing the mean values of conventional, digital and $\mathrm{CBCT}$ radiographic methods in measuring transportation and centering ability in PTU group.

the mean centering ability when ProTaper Universal instruments were used $(\mathrm{P} \leq 0.05)$. Mann-Whitney $\mathrm{U}$ test with Bonferroni adjustment test revealed that CBCT radiographic method showed the statistically highest mean centering ratio. However, there was no statistically significant difference in the mean centering ratio produced by conventional and digital radiographic methods when ProTaper Universal instruments were used.

\section{DISCUSSION}

High quality instrumentation of the root canal is crucial for the prevention or healing of apical diseases. According to Hülsmann et al ${ }^{(1)}$, "there are seven goals of root canal instrumentation: removal of vital and necrotic tissue from the main root canal space, creation of sufficient space for irrigation and medication, preservation of the integrity and location of the apical anatomy, avoidance of iatrogenic damage to the canal system and root structure, facilitation of canal filling, avoidance of further irritation and/or infection of the periradicular tissues, and preservation of sound root dentin to allow long-term function of the tooth". Respecting all of these goals may be challenging especially when preparing root canals with moderate or severe curvatures. 
ProTaper Universal (PTU) instruments, which is a rotary system of conventional NiTi wire that has been widely used ${ }^{(6,16)}$. Recently, ProTaper Gold (PTG) instruments were introduced, where they have design features with identical geometries as PTU but are more flexible as it has been developed through a patented proprietary thermomechanical process and advanced metallurgy ${ }^{(9)}$. ProTaper Gold (PTG) and ProTaper Universal instruments are distinctly different in their metallurgy. Therefore, the aim of the present study was to evaluate and compare the shaping abilities of ProTaper Gold and the ProTaper Universal systems using CBCT, digital and conventional radiographic techniques.

The current study was performed on the mesiobuccal root canals of extracted first mandibular molars, due to their anatomical characteristics, where most of them are round, narrow and curved ${ }^{(17)}$. Angle of curvatures ranging from $25^{\circ}-60^{\circ}$ according to Schneider's technique ${ }^{(14)}$, are considered endodontic cases with moderate to severe curvatures according to American Association of Endodontics (AAE).

Three levels were chosen representing the apical, middle and coronal thirds of the root canal. The first level was established at $3 \mathrm{~mm}$ from the apex representing the apical third of the canal at which apical transportation and zips often occurs ${ }^{(18)}$. While, the second and third levels were established at 6 and $9 \mathrm{~mm}$ representing critical levels at middle and coronal thirds respectively that are prone to stripping ${ }^{(16)}$. The apical preparation was completed to F2 file ( 0.25 tip size) as it has been reported that, the amount of canal transportation increases with apical preparation larger than \# $25^{(19)}$.

Traditionally, morphometric evaluation of root canal instrumentation was performed by serial axial sectioning of the samples ${ }^{(10)}$. However, this methodology compromises the integrity of the samples as it requires the samples' cutting. Moreover, previous authors reported difficulties in assessment because evaluation of an individual factor, such as changes in the internal canal dimensions due to instrumentation, required destruction of the tooth. This usually meant a loss of all data, except for that relating to a few predetermined levels. ${ }^{(20,21)}$.

The benefits to the patient should outweigh the potential risks of higher exposure to X-rays, especially with respect to the age of the patient as children and young adults are more sensitive to radiation damage ${ }^{(22)}$. Therefore, Vatech 1.5 HD image plate system was used in the present study, which provided reliable endodontic measurements even at very low exposures and better or even comparable image quality than the conventional film systems ${ }^{(23-25)}$.

Non-invasive CBCT scanning was used as it provides an accurate, reproducible, 3-dimensional evaluation of changes in root canal morphology before and after preparation without destruction of the samples ${ }^{(26)}$.

Samples were mounted in a custom-made siliconbased impression material to standardize the pre and post-instrumentation measurements. Additionally, paralleling device was used to maintain a fixed film/ sensor object distance and to ensure standardization of the direction of the X-ray beam, where it is perpendicular on the root canal ${ }^{(27,28)}$.

In the present study, both PTG and PTU instruments resulted in canal transportation at all examined levels (3, 6 and $9 \mathrm{~mm}$ from the root apex). PTG instruments recorded lower mean canal transportation compared to PTU instruments at 3,6 and 9mm levels when conventional, digital radiographic or CBCT radiography were used, with a statistically significant difference, at the coronal level $(9 \mathrm{~mm})$ when the conventional and digital radiographic methods were used; and at the apical level $(3 \mathrm{~mm})$ when CBCT radiographic method was used. PTG system presented overall less canal transportation compared to PTU system. As PTU and PTG systems have an identical geometrical design (convex triangular cross-sectional design, 
unique progressive variable taper along the flutes, noncutting tip design which allow easy penetration with minimal apical pressure) ${ }^{(26,29)}$ and operation mode, this result may be solely explained by their different manufacturing processes (the proprietary heat treatment technology), which clearly affect their stress-strain distribution patterns and bending behaviours, making PTG files more flexible and decreasing their tendency to straighten in curved canals ${ }^{(4,30)}$.

The results of canal transportation of PTG instruments were comparable to the results obtained with previous studies, in which PTG instruments were reported to have significantly less mean of canal transportation at all levels than PTU instruments ${ }^{(4,30)}$.The results of the present study was supported by previous studies that compared transportation by $\mathrm{M}$-wire and $\mathrm{CM}$ wire systems with those made of conventional $\mathrm{NiTi}$ and reported that $\mathrm{CM}$ wires produce less mean canal transportation than conventional NiTi wires ${ }^{(4-8)}$.

On the other hand, contradictory findings were reported by Elnaghy and Elsaka ${ }^{(29)}$, who reported that PTG and PTU systems showed no statistically significant difference in the mean transportation at the apical level when CBCT radiographic method was used. This could be attributed to the use of different canal curvature range $\left(25^{\circ}-30^{\circ}\right)$ than the current study.

It has been concluded that apical transportation greater than $0.3 \mathrm{~mm}$ may have a negative effect on the apical seal during obturation ${ }^{(31)}$. In the present study, none of the instrumented samples reached the above-mentioned critical level of transportation on all studied levels. This was consistent with previous study using PTG and PTU instruments ${ }^{(29)}$.

The results of canal transportation that were recorded in the present study were supported by the results of centering ratio, where PTG instruments produced significantly higher mean centering ratio compared to PTU instruments at the apical level when conventional or CBCT radiographic methods were used. Many studies have shown that instruments that are more flexible produce more centered root canal preparations ${ }^{(4,18,32)}$.

Many authors reported that the PTG instruments maintained the original root anatomy in curved canals and were able of producing centered preparations ${ }^{(4,7,30)}$.

On the contrary, many authors reported that, there was no statistically significant difference between PTG instruments and PTU instruments in the mean centering ratio ${ }^{(29,33)}$. This could be attributed to the use of different canal curvature range and different evaluation methods than the current study.

The quality and quantity of information obtained from radiographic investigations are very important as these data affect diagnosis, treatment plan and prognosis in endodontic therapy ${ }^{(11)}$. In clinical work; conventional and digital radiographs did not provide enough data on the pathological conditions (12). The use of CBCT allow gathering information at low radiation dose which equals two exposures by intra-oral radiography and $1 / 100$ to $1 / 30$ by medical $\mathrm{X}$-ray CT in short as 18 seconds of exposure time ${ }^{(34)}$. In the present study, CBCT was used to evaluate the dentin thickness and root canals of the selected mandibular molars. This technique permits visualization of the root canal system in three planes (axial-coronal- sagittal) that provide the most accurate pre and post- instrumentation measurements of the root canal transportation, centering abilities of the instruments used during treatment and analyse the amount of dentin removed during endodontic treatment $(13,35,36)$. These measurements were compared to the measurements obtained from the conventional and digital radiography.

The present study revealed that, there was a statistically significant difference among the three radiographic methods when ProTaper Gold instruments were used, where the CBCT radiographic method showed the statistically 
significant highest mean canal transportation. The results of the present study were in agreement with previous studies which found that $\mathrm{CBCT}$ provides a more accurate detection of hard tissue minimal changes ${ }^{(11,13)}$.

\section{CONCLUSIONS}

Within the limitations of this study the following could be concluded:

1. ProTaper Gold instruments are more able to maintain the original canal configuration than did ProTaper Universal instruments considering canal transportation and centering ability.

2. CBCT proved to present more details than conventional and digital periapical radiographs.

\section{REFERENCES}

1. Hülsmann M, Peters OA, Dummer PMH. Mechanical preparation of root canals : shaping goals, techniques and means. Endod Top. 2005; 10:30-76.

2. Schäfer E and Dammaschke T. Development and sequelae of canal transportation. Endod Top. 2009; 15:75-90.

3. Zhou H, Peng B, Zheng YF. An overview of the mechanical properties of nickel-titanium endodontic instruments. Endod Top. 2013; 29:42-54.

4. Gagliardi J, Versiani MA, De Sousa-Neto MD, PlazasGarzon A, Basrani B. Evaluation of the shaping characteristics of ProTaper Gold, ProTaper NEXT, and ProTaper Universal in curved canals. J Endod. 2015; 41:1718-24.

5. Marzouk AM and Ghoneim AG. Computed tomographic evaluation of canal shape instrumented by different kinematics rotary nickel-titanium systems. J Endod. 2013; 39:906-9.

6. Capar ID, Ertas H, Ok E, Arslan H, Ertas ET. Comparative study of different novel nickel-titanium rotary systems for root canal preparation in severely curved root canals. J Endod. 2013; 40:852-6.

7. Mamede-Neto I, Borges AH, Guedes OA, De Oliveira D, Pedro FLM, Estrela C. Root canal transportation and centering ability of nickel-titanium rotary instruments in mandibular premolars assessed using cone-beam computed tomography. Open Dent J. 2017; 11:71-8.
8. Van der Vyer PJ, Paleker F, Vorster M, De Wet FA. Root canal shaping using nickel titanium, m-wire, and gold wire: a micro-computed tomographic comparative study of one shape, protaper next, and waveone gold instruments in maxillary first molars. J Endod 2019; 45:62-67.

9. Elnaghy AM and Elsaka SE. Mechanical properties of ProTaper Gold nickel-titanium rotary instruments. Int. Endod. J. 2016: 49:1073-8.

10. Bramante CM, Berbert A, Borges RP. A methodology for evaluation of root canal instrumentation. J Endod. 1987; $13: 243-5$

11. Stavropoulos A and Wenzel A. Accuracy of cone beam dental CT, intraoral digital and conventional film radiography for the detection of periapical lesions. An ex vivo study in pig jaws. Clin Oral Investig. 2007; 11:101-6.

12. Patel S, Dawood A, Mannocci F, Wilson R, Ford TP. Detection of periapical bone defects in human jaws using cone beam computed tomography and intraoral radiography. Int Endod J. 2009; 42:507-15.

13. Green PT, Mol A, Moretti AJ, Tyndall DA, Kohltfarber HB. Comparing the diagnostic efficacy of intraoral radiography and cone beam computed tomography volume registration in the detection of mandibular alveolar bone defects. Oral Surg Oral Med Oral Pathol Oral Radiol Endod. 2019; 128:176-185.

14. Schneider SW. A comparison of canal preparations in straight and curved root canals. Oral Surg Oral Med Oral Pathol. 1971; 32:271-5.

15. Maitin N, Arunagiri D, Brave D, Maitin SN, Kaushik S, Roy S. An ex vivo comparative analysis on shaping ability of four NiTi rotary endodontic instruments using spiral computed tomography. J Conserv Dent. 2013; 16:219-33.

16. Abdel Kader KG. Evaluation of the shaping abilities of three rotary Ni-Ti systems ; Wave One, ProTaper Next \& ProTaper Universal in preparing curved root canals using cone beam computed tomography(CBCT). Egy Dent J. 2015; 61:1409-19.

17. De Pablo OV, Estevez R, Peix-Sanchez M, Heilborn C, Cohenca N. Root anatomy and canal configuration of the permanent mandibular first molar: a systematic review. J Endod. 2010; 36:1919-31.

18. Gergi R, Osta N, Bourbouze G, Zgheib C, Arbab-Chirani R, Naaman A. Effects of three nickel titanium instrument systems on root canal geometry assessed by microcomputed tomography. Int Endod J. 2014; 48:162-70. 
19. Shivashankar MB, Niranjan NT, Jayasheel A, Kenchanagoudra MG. Computed tomography evaluation of canal transportation and volumetric changes in root canal dentin of curved canals using Mtwo, ProTaper and ProTaper next rotary system-an in-vitro study. J Clin Diagn Res. 2016; 10: ZC10-4.

20. Freire LG, Gavini G, Cunha RS, Dos Santos M. Assessing apical transportation in curved canals: comparison between cross-sections and micro-computed tomography. Braz Oral Res. 2012; 26:222-7.

21. Nielsen RB, Alyassin AM, Peters DD, Carnes DL, Lancaster J. Microcomputed tomography: An advanced system for detailed endodontic research. J Endod. 1995; 21:561-8.

22. Bürklein S, Börjes L, Schäfer E. Comparison of preparation of curved root canals with Hyflex CM and Revo-S rotary nickel-titanium instruments. Int Endod J. 2014; 47:470-6.

23. Rasimick BJ, Shah RP, Musikant BL, Deutsch AS. Radiopacity of endodontic materials on film and a digital sensor. J Endod. 2007; 33:1098-101.

24. Patel S, Dawood A, Whaites E, Ford TP. New dimensions in endodontic imaging: Part 1. Conventional and alternative radiographic systems. Int Endod J. 2009; 42:447-62.

25. Mohtavipour ST, Dalili Z, Azar NG. Direct digital radiography versus conventional radiography for estimation of canal length in curved canals. Imaging Sci Dent. 2011; 41:7-10.

26. Hashem AAR, Ghoneim AG, Lutfy RA, Foda MY, Omar GAF. Geometric analysis of root canals prepared by four rotary NiTi shaping systems. J Endod. 2012; 38:996-1000.

27. Saber SED, Nagy MM, Schäfer E. Comparative evaluation of the shaping ability of ProTaper Next, iRaCe and Hyflex CM rotary NiTi files in severely curved root canals. Int Endod J. 2015; 48:131-6.
28. Saber SED, Nagy MM, Schäfer E. Comparative evaluation of the shaping ability of WaveOne, Reciproc and OneShape single-file systems in severely curved root canals of extracted teeth. Int Endod J. 2015; 48:109-14.

29. Elnaghy AM and Elsaka SE. Shaping ability of ProTaper Gold and ProTaper Universal files by using cone-beam computed tomography. Indian J. Dent. Res. 2016; 27: 37-41.

30. Silva EJN, Muniz BL, Pires F, Belladonna FG, Neves AA, Souza EM, et al. Comparison of canal transportation in simulated curved canals prepared with ProTaper Universal and ProTaper Gold systems. Restor Dent Endod. 2016; 41:1-5.

31. Wu MK, Fan B, Wesselink PR. Leakage along apical root fillings in curved root canals. Part I: effects of apical transportation on seal of root fillings. J Endod. 2000; 26:210-6.

32. Short JA, Morgan LA, Baumgartner JC. A Comparison of canal centering ability of four instrumentation techniques. J Endod. 1997; 23:503-7.

33. Arslan H, Yildiz ED, Gunduz HA, Sumbullu M, Bayrakdar IS, Karatas E, Sumbullu MA. Comparative study of ProTaper gold, reciproc, and ProTaper Universal for root canal preparation in severely curved root canals. J Conserv Dent. 2017; 20:222-4.

34. Kara Ü, Yildirim D, Akkurt I. Radiation dose in dental radiology. Acta Phys. Pol. A 2016; 130, 407-8.

35. Amer WS and Sabet NE. Comparison of cone beam computed tomography, periapical and panoramic radiography in evaluating periapical lesions: A clinical study. Egy Dent J. 2014; 60:809-16.

36. Xu J, He J, Yang Q, Huang D, Zhou X, Peters OA, et al. Accuracy of cone-beam computed tomography in measuring dentin thickness and its potential of predicting the remaining dentin thickness after removing fractured instruments. J Endod. 2017; 43:1522-7. 